\title{
COMPARISON OF SPIDER DIVERSITY IN TWO TEMPERATE FORESTS BY A RAPID SURVEY AND ITS POTENTIAL IN NATURE CONSERVATION STUDIES
}

\author{
KostanjŠEK, R. ${ }^{*}$ - KURALT, Ž. - SiVEC, N. - VelKaVRH, M. \\ University of Ljubljana, Biotechnical Faculty, Department of Biology, Večna pot 111, 1000 \\ Ljubljana, Slovenia \\ (phone: +3861-320-33-73; fax: +3861-257-33-90) \\ *Corresponding author \\ e-mail:rok.kostanjsek@bf.uni-lj.si
}

(Received $31^{\text {st }}$ Oct 2014; accepted $1^{\text {st }}$ Dec 2014)

\begin{abstract}
One of the crucial issues in nature conservation studies refers to the significant investment of time and energy required for a reliable estimation of biodiversity. To overcome this problem we designed a short survey for the estimation the richness of spider species in comparable habitats based on a semiquantitative approach. Carrying out the survey in protected and unprotected temperate forest in the northeast Slovenia provided sufficient data for evaluation and relative comparison of spider diversity between the forests. High diversity of spiders observed in both forests indicates their importance as refuge habitats in agriculturally degraded landscape. At the same time, the comparison between surveyed forests shows a significantly higher level of spider diversity in the protected one, which supports the current conservation acts and provides a base-line for future monitoring of spider diversity in the forest. Modified set of sampling methods used in the survey revealed high level of efficiency in sampling by hand-held suction device and suggests its potential as an additional method in spider diversity studies in temperate forests with dense undergrowth. As the study is based on one of the most diverse and abundant animal groups in terrestrial ecosystems, it provides a reliable comparison of estimated biodiversity between comparable sites and exhibits the potential to complement the current criteria for assignment and monitoring of the biodiversity required for efficient conservation planning.
\end{abstract}

Keywords. species richness, diversity estimation, spiders, protected areas

\section{Introduction}

The data on relative abundance, distribution and richness of taxa provide base-line information in ecological studies and a crucial background for conservation planning (Blackmore, 1996; Humphries et al., 1995; Magurran, 2004, 1988; May, 1988; Raven and Wilson, 1992). As knowing the exact number and identity of each species in the area of interest is close to impossible, evaluations of biodiversity are commonly based on estimation of species richness of a selected group of organisms. In that view the arthropods were neglected until the past decade, when several studies proved their suitability in biodiversity studies over other organisms (e.g. Gregory et al., 2003; Sergio et al., 2006). Apart from the large number of species and an abundance of specimens, the important advantage of the arthropods in biodiversity-assessment studies is their fast growth rate and shorter generation spans, which enables their quick response to anthropogenic and natural changes of environmental conditions (Favila and Halffter, 1997; Kremen et al., 1993).

Spiders are amongst the most diverse, numerous and widespread groups of intermediate-level predators in terrestrial ecosystems, which rapidly colonize available habitats and exploit various niches (Coddington and Levi, 1991; Marc et al., 1999; Wise, 1993). As their distribution is strongly influenced by the habitat structure and the 
vegetation parameters (Buddle et al., 2000; De Souza and Martins, 2004; Greenstone, 1984; Petillon and Garbutt, 2008; Uetz, 1991; Wheater et al., 2000), spiders are recognized as an appropriate indicator group of organisms in biodiversity studies (Coddington et al., 1991; Platnick, 1999).

Although the spiders can be sampled by common methods used for terrestrial arthropods, a combination of methods targeting spiders in different microhabitats is required for objective estimation of biodiversity (Cardoso et al., 2008). On these grounds, a sampling protocol based on a repetitive series of semi-quantitative samplings has been designed for estimating the richness of spider species in tropical forests (Coddington et al., 1991). The protocol and the sampling methods applied have proven adequate for capturing a large number of species and specimens, while the diversity estimators used in the study (Gotelli and Colwell, 2010) enabled comparison of biodiversity between similar habitats (Ryndock et al., 2012). In the following studies, the initial protocol has been modified and successfully applied in various habitats (Cardoso, 2009; Cardoso et al., 2008; Coddington et al., 1996; Dobyns, 1997; JimenezValverde and Lobo, 2006; Muelelwa et al., 2010; Silva et al., 1996; Sørensen et al., 2002; Toti et al., 2000), including European temperate forests (Kuntner and Kostanjšek, 2000; Kuntner, 1999; Scharff et al., 2003).

Determination of priority areas for conservation and assessment of conservation effects, based on biodiversity values, are one of the major issues addressed in conservation studies, which are commonly related to considerable investments of time, energy and expertise (Groves et al., 2002; Humphries and Parenti, 1999; Myers et al., 2000; Tracy and Brussard, 1994). In order to credibly compare the richness of spider species between protected and unprotected temperate forest with minimal effort, we designed a rapid survey based on semi-quantitative approach (Coddington et al., 1991). To increase the sampling efficiency and reduce the sampling time, we expand the set of sampling methods by a hand-held suction device and compare its efficiency to five methods commonly used in spider richness estimation studies. The potential of short surveys based on spider diversity in assessment of conservation priorities and effects is also discussed.

\section{Methods}

\section{Study area}

The study was carried out in two comparable temperate forests surrounded by agricultural land in Dravsko polje lowland in the north-eastern Slovenia. Both forests are about $250 \mathrm{~m}$ above sea levels and share the same climate conditions. The samplings were carried out in a one hectare square plot within each forest. The distance from plots to the nearest non-forest habitat was at least 250 meters in order to avoid the edge effects.

First plot, named "Rače", was located within forest recognized as Piceo abietis Quercetum roboris in Rački ribniki - Požeg Regional Park, measuring $5 \mathrm{~km}^{2}$, at $\mathrm{N}$ $46^{\circ} 25,8^{\prime}$ E $15^{\circ} 40,7^{\prime}$. The second plot, named 'Marjeta", was selected within a patch of forest recognized as Galio rotundifolii - Pinetum sylvestris, measuring $4,5 \mathrm{~km}^{2}$ and located 5,8 $\mathrm{km}$ northeast from the first one, at $\mathrm{N} 46^{\circ} 25,8^{\prime} \mathrm{E} 15^{\circ} 40,7^{\prime}$. 


\section{Sampling methods}

The methods considered to cover most of the microhabitats include five wellestablished methods for spider samplings in similar protocols (Cardoso et al., 2008; Coddington et al., 1996). (1) "Ground" - selective spider sampling by hand, forceps or aspirator below the knee-level. (2) "Aerial" - selective sampling by the above mentioned methods above the knee-level, up to the height of the collector's reach. (3) "Sweep" - sampling of vegetation by round sweeping nets, with a diameter of $30 \mathrm{~cm}$. (4) "Sifter" - sifting of leaf litter by filed sieve with diameter of $30 \mathrm{~cm}$ and mesh size of $5 \times 5 \mathrm{~mm}$ over a white cloth, after which the spiders were collected with an aspirator. (5) "Pitfall" - traps consisting of cups with diameter of $15 \mathrm{~cm}$ filled with ethylene glycol were set $1 \mathrm{~m}$ apart from each other. Besides these, an additional method was tested for its ability to complement the sampling methods listed above. The method, referred to as "blower" hereafter, includes hand-held suction device - the reversed leaf blower with two-cycle gasoline engine (BVM 250, McCulloch) equipped with a rigid suction tube with diameter of $11 \mathrm{~cm}$. Suction opening was covered by standard-size aerial insect net, which prevented sampled spiders to be sucked into the machine. After two minutes of sampling, the net contents were emptied onto a white sheet. An aspirator was then used to collect the spiders from the sheet.

\section{Design of the study}

The samplings were performed between 18th and 24th of July 2013 and include 32 sampling units in each plot. The sampling design was semi-quantitative, with a sampling unit defined as one hour of effective sampling by one person using one sampling method. The sampling units were equally divided between the methods (Coddington et al., 1991), with three hours of sampling per plot of aerial, ground, sweep and sifter by day and three hours by night. Day samples were collected between 9:30 and 13:30 and night samples between 22:00 and 1:00.

Twelve pitfall traps were set in each plot and left during the sampling period, after which three adjacent traps from the same plot were combined to form 'one sampling unit'. Therefore, effort in a field per sample was comparable with the other sampling techniques (Cardoso, 2009). The duration of sampling unit for blower was arbitrarily determined to be 2 minutes of intense sampling instead of one hour, due to the previously described sampling efficiency of the method (Buffington and Redak, 1998; Samu et al., 1997).

Four collectors worked simultaneously in both plots, rotating the methods between them to reduce the sampling efficiency bias due to collector's experience (Coddington et al., 1996). In order to avoid the sampling fatigue the number of samples per day was restricted to two samplings in the daytime and two in the nighttime (Dobyns, 1997).

The weather during the samplings was constant, without noticeable precipitation and temperature fluctuations.

\section{Statistical analysis}

Only adult specimens were considered for statistical analysis, given that determining of the species in juveniles tends to be difficult and unreliable. The collected spiders were determined to a species level when possible. Otherwise, the specimens were assigned to morphospecies based on their genital morphology. All the collected material is deposited at Department of Biology, Biotechnical Faculty, University of Ljubljana. 
To compare the species richness between both plots, the richness was estimated through randomized accumulation curves calculated for each plot by Estimate $\mathrm{S}$ program (Win 9.1) (Colwell, 2013). Accumulation curves based on seven commonly used species richness estimators, namely ACE, ICE, Chao1, Chao2, Jack1, Jack2, and Michaelis-Menten (Gotelli and Colwell, 2010), were calculated using one hundred randomizations. To compare the estimated species richness between the plots, an average accumulation curves were calculated for each plot from the mean values of all seven estimators and tested by a two-tailed Student's t-test. The dynamics of the final segments of each accumulation curve was described through the slope values calculated as reported previously (Cardoso et al., 2008). Average of estimators at the end of the survey was used in calculation of inventory completeness, defined as the coefficient between observed and estimated species richness (Coddington et al., 1996). As crude measure of sampling effort the sampling intensity was calculated for each method, as the ratio of collected specimens to species (Coddington et al., 1996).

\section{Results}

Over a five day survey, 32 sampling units in each plot yielded 228 adult specimens belonging to 67 species in Rače and 264 specimens belonging to 61 species in Marjeta plot (Table 1). List of collected species according to plot and methods are given in Appendix 1.

Table 1. Estimation of species richness in both sampling plots

\begin{tabular}{|c|cc|}
\hline sampling plot & Rače & Marjeta \\
\hline observed species richness & 67 & 61 \\
\hline estimated species richness: & & \\
ACE estimator & 126,1 & 103,1 \\
ICE estimator & 154,1 & 108,2 \\
Chao1 estimator & 124,8 & 103,1 \\
Chao2 estimator & 221,1 & 107,6 \\
Jack1 estimator & 108,7 & 92 \\
Jack2 estimator & 143,5 & 112 \\
Michaelis-Menten estimator & 118,2 & 97,5 \\
\hline average of estimates & 142,6 & 103,3 \\
\hline completness (\%) & 47 & 64,9 \\
\hline
\end{tabular}

Higher species richness in Rače comparing to Marjeta plot was indicated by a higher number of observed species and further confirmed by the values of estimated species calculated from all seven estimators (Table 1). The latter varied between 92 and 112 species in Marjeta and between 108,7 and 143,5 species in Rače, with averages of 103,3 and 142,6 species for Marjeta and Rače, respectively (Table 1). Regardless the plot, the highest estimates were given by Chao 2 and the lowest by Jack1 estimator. Average estimated species richness of each plot was used to calculate the inventory completeness, which was just below $65 \%$ in Marjeta and $47 \%$ in Rače (Table 1 ). The randomized accumulation curves of all seven estimators have not reached the asymptote at the end of the sampling in both plots (Figure 1). While the slopes of the accumulation 
curves for all estimators in Marjeta plot tend to gradually settle around 100 species, the curves continue to rise continuously in Rače plot (Figure 1b).

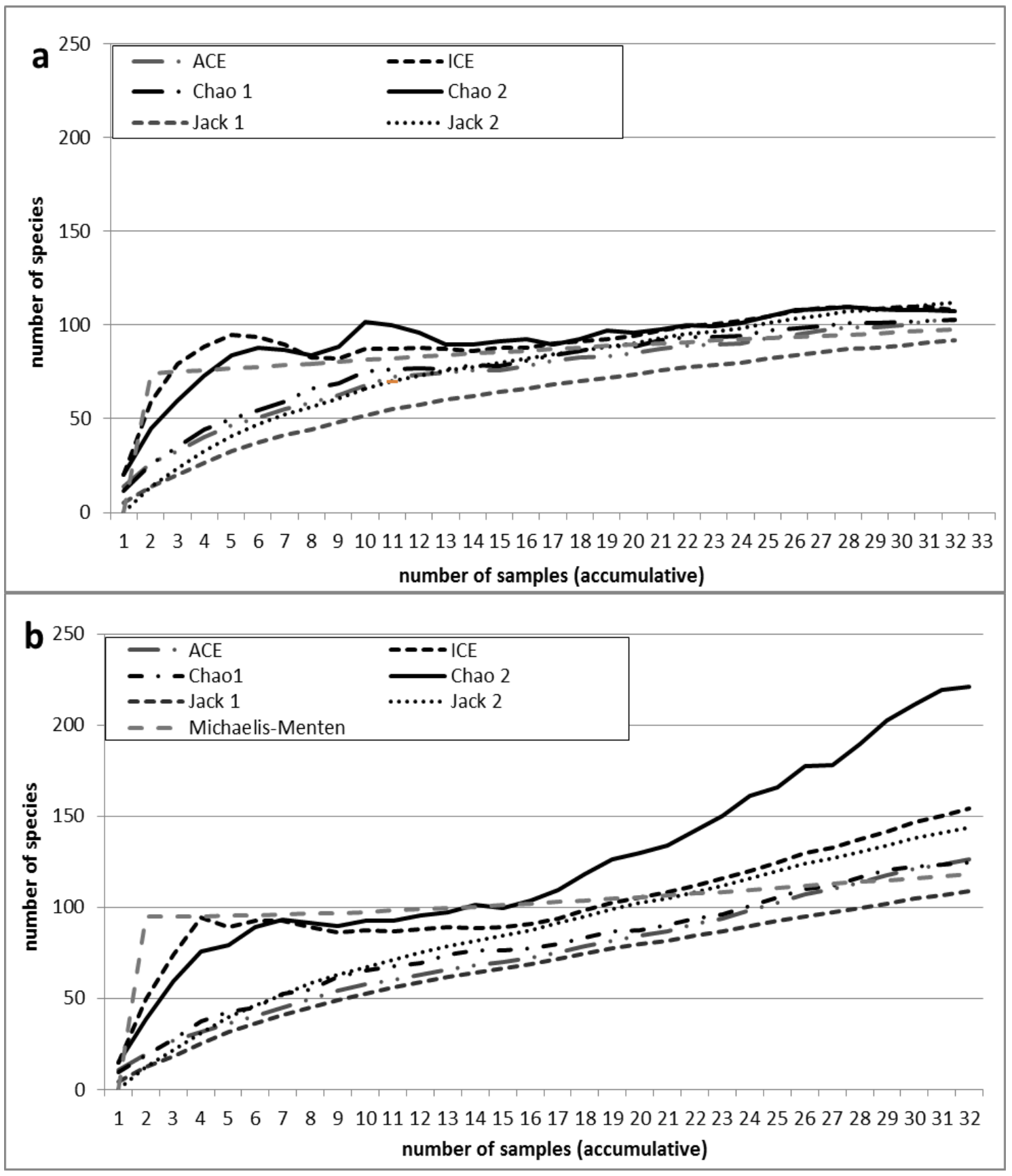

Figure 1. Randomized species accumulation curves of seven estimators for Marjeta (a) and Rače plot (b).

To compare the species richness between the plots, an average accumulation curve was calculated for each plot using all seven estimators (Figure 2). The dynamics of average accumulation curves for both plots were almost identical at their beginnings and slowly diverge as the number of summarized samples passes twelve. As indicated by the curved of individual estimators, the average curve from Rače continues to rise steadily, 
with the slope value at the end of the curve of 0,185 , while the rise of Marjeta curve tends to slow down, with the slope value of 0,132 .

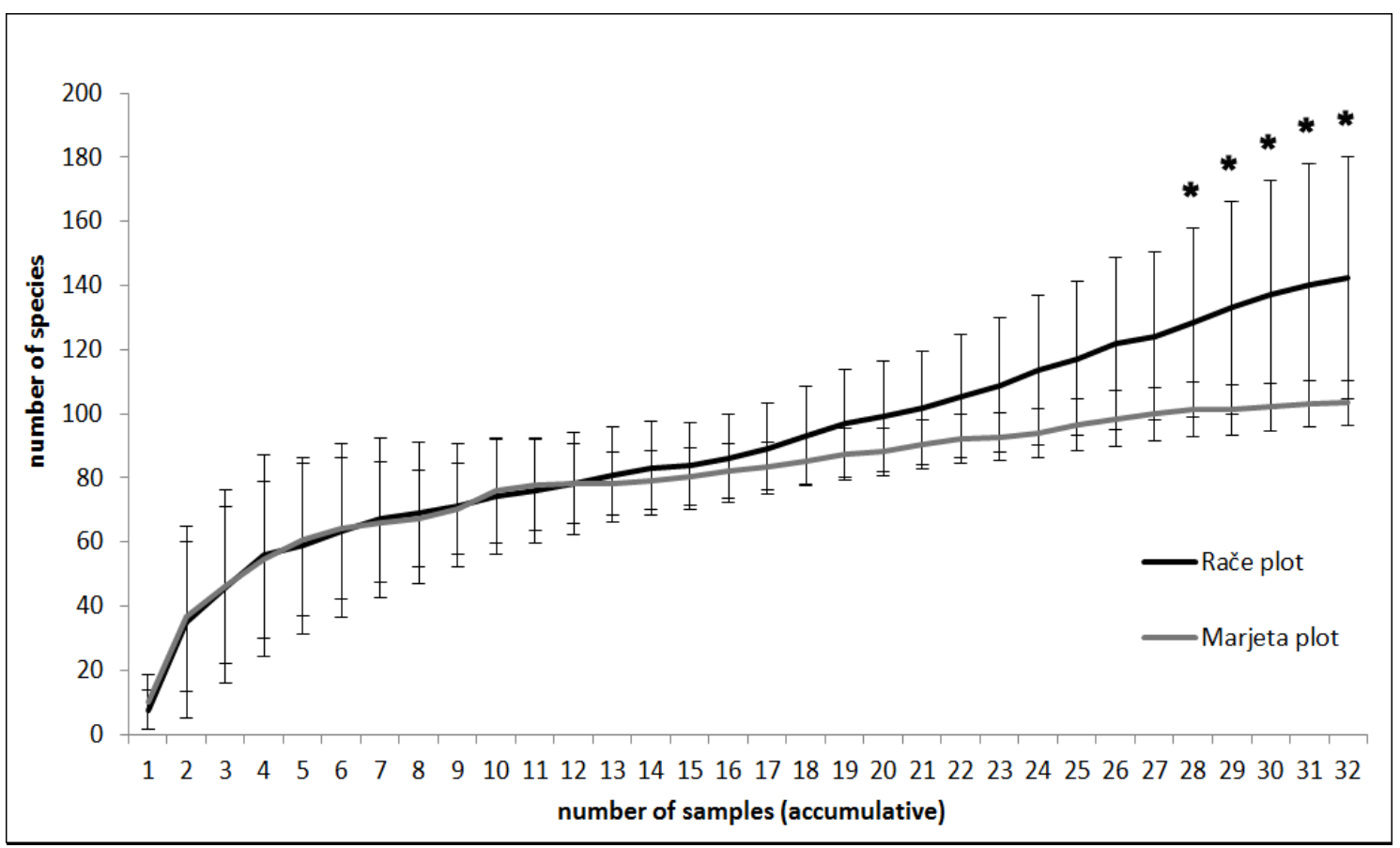

Figure 2. Average accumulation curves for Rače and Marjeta plot. Curves are calculated as the average of seven estimators (ACE, ICE, Chao 1, Chao 2, Jack 1, Jack 2 and Michaelis-Menten), with standard deviations. Asterisks indicate the statistically significant difference $(p>0,05)$ between the average species richness estimates in the plots.

Standard deviations depicted on both average curves (Figure 2) reflect the variability of the individual estimators shown in Figure 1. Gradual approaching of estimators to the asymptote in the Marjeta plot (Fig, la) attributes in decrease of standard deviation values towards the end of the average Marjeta curve (Figure 2). On the other hand, the diverged paths of estimator's curves in Rače (Figure $1 b$ ), results as gradual increase of the standard deviations in average Rače curve (Figure 2). Nevertheless, the differences in estimated species richness between the plots becomes statistically significant after 27 summarized samples, when the 'p values' fall below 0,05 (Figure 2).

The efficiency of the used sampling methods was evaluated according to the number of collected specimens, species and unique species per sample, where the latter refers to species collected by one method only (Table 2, Figure 3). Among the unselective or 'tool-based' methods, the traps yielded the highest number of individuals per sample. The traps were followed by the sweep net and blower, while sifter provided the lowest numbers of specimens. The number of collected individuals by selective methods (i.e. aerial and ground) was comparable to sifter. The only exception was a ground sampling in Marjeta by night, where the yield of individuals was comparable to the sweep net (Table 2). These methods also provided the highest number of species and, together with blower in Marjeta, the highest number of unique species per sample as well (Table 2). The sampling intensity varied between 1 and 3 for most of the sampling methods, except for the pitfall traps, for which the values of 4,23 were calculated (Table 2). 
Table 2. Efficiency of sampling methods in Rače (R) and Marjeta (M) plots. SIF, SW, GRO, $A E R, B L O$ and TRAP stand for sifting, sweep net, ground, aerial, blower and pitfall traps, respectively. $D$ - day samplings, $N$ - night samplings.

\begin{tabular}{|c|c|c|c|c|c|c|c|c|c|c|c|c|c|c|c|c|c|c|c|c|c|c|}
\hline & \multicolumn{2}{|c|}{ SIF D } & \multicolumn{2}{|c|}{ SIF N } & \multicolumn{2}{|c|}{ SW D } & \multicolumn{2}{|c|}{ SW N } & \multicolumn{2}{|c|}{ GRO D } & \multicolumn{2}{|c|}{ GRO N } & \multicolumn{2}{|c|}{ AER D } & \multicolumn{2}{|c|}{ AER N } & \multicolumn{2}{|c|}{ BLO } & \multicolumn{2}{|c|}{ TRAP } & \multicolumn{2}{|c|}{ TOTAL } \\
\hline & $\mathrm{R}$ & M & $\mathrm{R}$ & M & $\mathrm{R}$ & M & $\mathrm{R}$ & M & $\mathrm{R}$ & M & $\mathrm{R}$ & M & $\mathrm{R}$ & M & $\mathrm{R}$ & M & $\mathrm{R}$ & M & $\mathrm{R}$ & M & $\mathbf{R}$ & M \\
\hline samples & 3 & 3 & 3 & 3 & 3 & 3 & 3 & 3 & 3 & 3 & 3 & 3 & 3 & 3 & 3 & 3 & 4 & 4 & 4 & 4 & 32 & 32 \\
\hline individuals & 9 & 19 & 10 & 5 & 38 & 39 & 30 & 34 & 13 & 19 & 18 & 34 & 2 & 17 & 17 & 22 & 37 & 15 & 55 & 60 & 228 & 264 \\
\hline individuals/sample & 3 & 6,3 & 3,3 & 1,7 & 12,7 & 13 & 10 & 11,3 & 4,3 & 6,3 & 6 & 11,3 & 0,7 & 5,7 & 5,7 & 7,3 & 9,3 & 3,8 & 13,8 & 15 & 7,1 & 8,3 \\
\hline species & 7 & 13 & 7 & 4 & 16 & 18 & 15 & 14 & 8 & 6 & 13 & 18 & 2 & 6 & 6 & 8 & 14 & 11 & 13 & 15 & 67 & 61 \\
\hline species/sample & 2,3 & 4,3 & 2,3 & 1,3 & 5,3 & 6 & 5 & 4,7 & 2,7 & 2 & 4,3 & 6 & 0,7 & 2 & 2 & 2,7 & 3,5 & 2,8 & 3,3 & 3,8 & 2,1 & 1,9 \\
\hline unique species & 2 & 3 & 3 & 0 & 6 & 6 & 3 & 2 & 1 & 0 & 4 & 6 & 0 & 2 & 0 & 0 & 8 & 1 & 5 & 3 & 32 & 23 \\
\hline unique species/sample & 0,7 & 1 & 1 & 0 & 2 & 2 & 1 & 0,7 & 0 & 0 & 1,3 & 2 & 0 & 0,7 & 0 & 0 & 2 & 0,3 & 1,3 & 0,8 & 1 & 0,7 \\
\hline sampling intensity & 1,3 & 1,5 & 1,4 & 1,3 & 2,4 & 2,2 & 2 & 2,4 & 1,6 & 3 & 1,4 & 1,9 & 1 & 2,8 & 2,8 & 3 & 2,6 & 1,4 & 4,2 & 4 & $\mathbf{3 , 4}$ & 4,3 \\
\hline
\end{tabular}

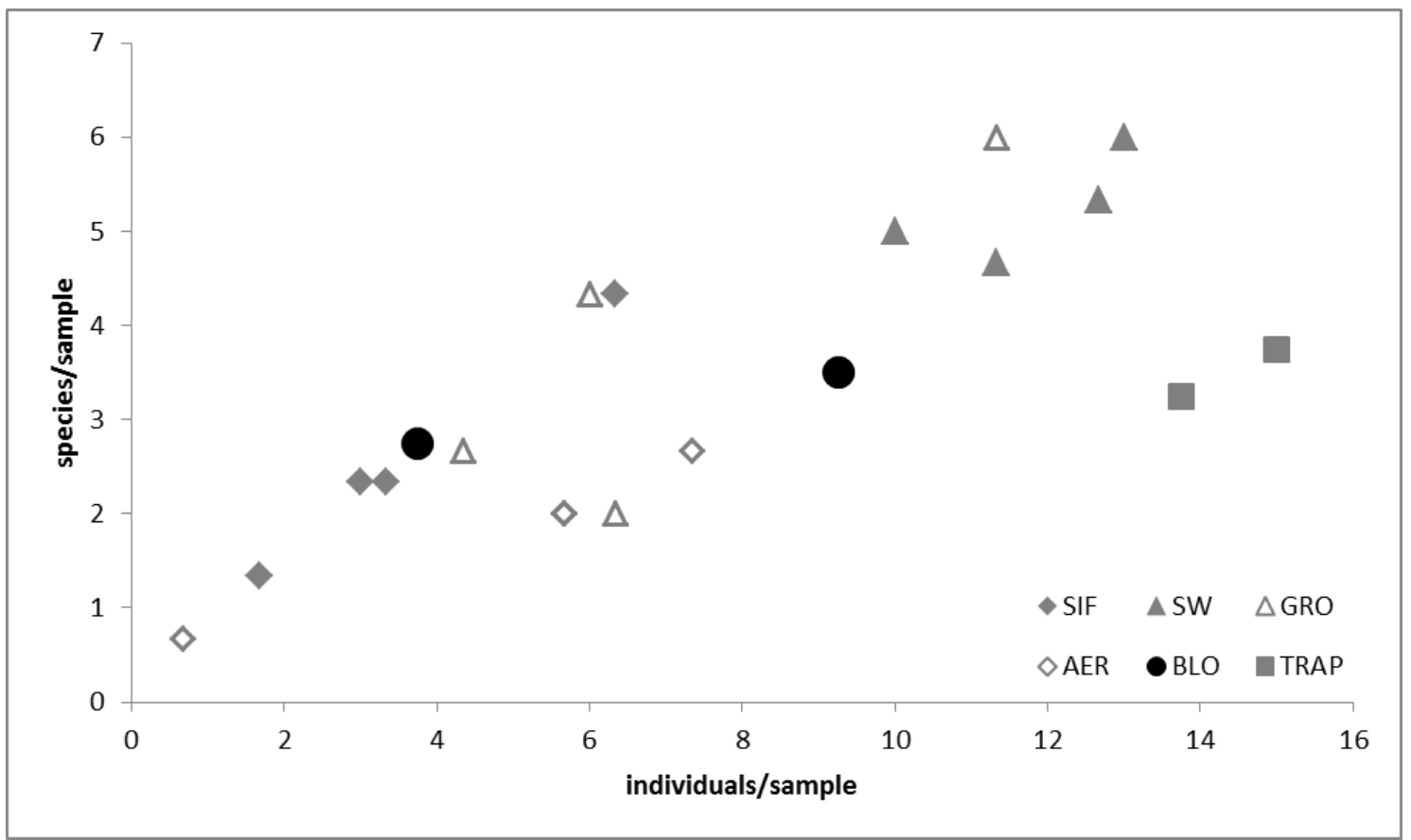

Figure 3. The effectiveness of the sampling methods shown as the number of collected specimens and species per sample. SIF, SW, GRO, AER, BLO and TRAP stand for sifting, sweep, ground, aerial, blower and pitfall traps, respectively. $D$ - day samplings, $N$ - night samplings.

\section{Discussion}

An increasingly important role of the richness estimation approach in biological inventory for assessment and conservation over the past decades (Barriga et al., 2010; Bonet et al., 2011; Cardoso et al., 2008; de Thoisy et al., 2008; MacLeod et al., 2011; Merlo et al., 2010; Schoeman et al., 2008), and the recognition of spiders as an indicator 
group of organisms in biodiversity studies (Coddington et al., 1991; Platnick, 1999) truggered studies on local spider richness in Slovenian forests. These were performed in several regions (Budja, 2008; Kuntner and Kostanjšek, 2000; Kuntner, 1997, 1996), including the sub-Pannonic region in the north-east of Slovenia (Kuntner, 1999) and generally followed the initial protocol (Coddington et al., 1991), with slight variations in the sampling methods and used estimators.

The estimated species richness in Rače and Marjeta plot exceeds the previous estimation of spider diversity in the north-western Slovenia (Kuntner, 1999) in which the spider diversity was estimated to between 72 to 86 species. With and average diversity estimation of 103 species, the diversity of Marjeta plot is comparable to the forests of subMediterranean region in south-western Slovenia (Kuntner and Kostanjšek, 2000; Kuntner, 1997), while spider richness in Rače plot with 142 estimated species is so far the highest one recorded in Slovenian forests. Compared to similar studies in other regions, the diversity of the surveyed plots is comparable to Appalachian hardwood coves (Coddington et al., 1996; Dobyns, 1997), which is one of the biotically richest regions of temperate North America and considerably exceeds the diversity of the deciduous forests in northern Europe (Scharff et al., 2003).

Regarding that in the inventory still sufficient to accurately estimate the biotic richness, the estimator curves should asymptote (Colwell and Coddington, 1994), most of the previous studies estimating the richness of spider species (Cardoso, 2009; Cardoso et al., 2008; Coddington et al., 2009, 1996; Muelelwa et al., 2010; Scharff et al., 2003), including the above mentioned studies in Slovenia can be considered undersampled. With only 32 sampling units per plot our study is no exception. Climbing accumulation curves described by relatively high slope values at their far ends and low sampling intensity, when compared to similar studies (Coddington et al., 2009, 1996; Scharff et al., 2003; Sørensen et al., 2002), are in accordance with low inventory completeness calculated for the both plots.

With uncompleted inventories, the diversity estimates in both spots are prone to undersampling bias (Coddington et al., 2009), which implies underestimation of already high diversity estimations. However, rather than an accurate estimation of spider diversity by exhaustive sampling, the aim of our survey was to establish a rapid survey method for reliable comparison of species richness between two adjacent and comparable habitats with minimal sampling effort. The latter includes minimization of the sampling units required for distinction of estimated biodiversity, which was achieved by less than thirty sampling units per plot.

Aside from the threat of undersampling bias, our study was designed to minimize previously recognized factors, which may influence the outcome of diversity estimation studies (Cardoso, 2009; Cardoso et al., 2008; Jimenez-Valverde and Lobo, 2006). These include avoidance of the juvenile specimens, minimization of the sampling fatigue and the influence of the collector experience, which were already addressed in the Materials and Methods chapter. As many species of spiders are nocturnal (Green, 1999), our study design also includes a balanced amount of daytime and nighttime samplings (Coddington et al., 1991). In accordance to previous studies in the temperate forests, the selective methods, for instance the aerial and ground methods, provided higher numbers of species and specimens in the night samplings, while the opposite can be observed for tool-based methods sweeping net and sifter, which proved more efficient in the daytime (Budja, 2008; Kuntner and Kostanjšek, 2000; Kuntner, 1996). Regarding the efficiency of the methods, the results were as expected and in accordance with previous works. Non- 
selective methods, the traps and the sweep net provided the highest number of specimens and species, while the efficiency of the sifter was lower (Coddington et al., 1996; Kuntner and Kostanjšek, 2000). Comparison of selective methods in our study confirmed previous reports on higher efficiency of ground over aerial sampling in temperate forests (Coddington et al., 1996; Dobyns, 1997; Kuntner and Kostanjšek, 2000; Kuntner, 1999, 1997; Scharff et al., 2003).

The sampling approaches used in spider species richness studies, following the initial protocol proposed by Coddington and co-workers (1991), commonly include four to five 'main' methods. Although the use of a constant set of methods allows for comparison of studies on similar habitats, regarding the estimated diversity, the adaptation of the methods to specific microhabitats and introduction of new sampling approaches are prerequisite for a reliable estimation of species richness (Cardoso et al., 2008). In that view we considered previous modifications to the sampling sets used in temperate forests (Budja, 2008; Coddington et al., 1996; Dobyns, 1997; Kuntner and Kostanjšek, 2000; Kuntner, 1999; Scharff et al., 2003) and introduced the hand-held reverse leaf blower as an additional method.

With availability of hand-held suction devices (Samu et al., 1997), which replaced the traditional suction devices as the D-vac (Dietrick, 1961) the suction sampling has become widely accessible and frequently used in arthropod surveys (Grootaert et al., 2010). It proved highly efficient and appropriate for spider sampling in various habitats (Bell et al., 2000; Borges and Brown, 2003; Dinter, 1995; Samu et al., 1997)). As an unselective, toolbased method, the blower is suitable for collectors with little or no previous field experience (Buffington and Redak, 1998). At the same time, its ability to retrieve the spiders from microhabitats on or close to the ground (Sanders and Entling, 2011), where spiders dwell regardless the time of the day, eliminates the need for a nighttime sampling.

Regarding the amount of retrieved species and specimens in our study, the blower efficiency is comparable to other unselective methods, which is in accordance with previous studies (Buffington and Redak, 1998). Sampling with the blower also provided a considerable number of unique species from both surveyed plots and therefore efficiently complements other methods in our study. Considering that the blower provided comparable yields of the spiders in two-minute sampling units, in comparison to one-hour samplings of the other methods, the blower may also significantly reduce the duration of similar surveys. By combining the short sampling time and sufficient yields of specimens and species required for reliable statistical analysis (Coddington et al., 1991), the blower has therefore considerable potential as an additional method in spider species richness studies in temperate forests with rich lower vegetation and grass.

As the biodiversity of the Dravsko polje flatland is influenced by the intense agricultural degradation of natural habitats, the observed spider diversity richness in the surveyed forest patches suggests their role as refuge habitats (Pirnat, 2000, 1991), generally recognized by significant biodiversity (Watts et al., 2005). Regardless the background, our study indicates the high biodiversity value and the importance of forest patches in degraded landscape of Dravsko polje, which was (at least to some extent) recognized with the establishment of Rački ribniki - Požeg Regional Park in 1992 (Medobčinski Uradni vestnik, 1992). As a habitat for endangered species listed in Habitats directive (SCI) (Uradni list RS, 2004) the park was assigned to Natura 2000 network.

With the ability to distinguish the estimated spider diversity between protected and unprotected forests in favor of the former, based on only 32 sampling units per plot, our study shows the potential to complement the current criteria for assignment and 
monitoring of the protected sites. Based on spiders, our study also exploits the terrestrial arthropod diversity, as a rich data source for conservation planning and management (Kremen et al., 1993) and provides a step towards a credible assessment of the biodiversity based on a comprehensive set of criteria, required for efficient conservation planning (Groves et al., 2002; Regan et al., 2007). As a short-termed study providing sufficient amount of data by simple and affordable sampling approach, our survey fulfills most of the requirements of conservation studies (Coddington et al., 1991; Humphries et al., 1995) at one side and avoids the puzzling effect of phenological changes caused by seasons (Coddington et al., 2009). Although the potential of our study as a biodiversity evaluation tool will be evaluated through future studies, the results already support and justify the conservation acts at the Rački ribniki regional park and provide a base-line for future monitoring of spider diversity in the park, based on the comparison to nonprotected forests in the region.

Acknowledgements. The authors wish to express their gratitude to Rok Šturm, Vid Leban, Polona Sušnik, Ana Gabrovec and Eva Rimahazi for the list of plant species in surveyed areas, to prof. dr. Andrej Blejec for constructive comments on statistical analysis and to Matej Križnar for proofreading the text.

\section{REFERENCES}

[1] Barriga, J. C., Lassaletta, L., Moreno, A. G. (2010): Ground-living spider assemblages from Mediterranean habitats under different management conditions. - J. Arachnol. 38: 258-269.

[2] Bell, J. R., Wheater, C. P., Henderson, R., Cullen, W. R. (2000): Testing the efficiency of suction samplers (G-vacs) on spiders: the effect of increasing nozzle size and suction time. - Eur. Arachnol. 285-290.

[3] Blackmore, S. (1996): Knowing the earth's biodiversity: Challenges for the infrastructure of systematic biology. - Science 274:63-64.

[4] Bonet, J., Ulefors, S.-O., Viklund, B., Pape, T. (2011): Species richness estimations of the megadiverse scuttle fly genus Megaselia (Diptera: Phoridae) in a wildfire-affected hemiboreal forest. - Insect Sci. 18:325-348.

[5] Borges, P. A., Brown, V. K. (2003): Estimating species richness of arthropods in Azorean pastures: the adequacy of suction sampling and pitfall trapping. - Graellsia 59:7-24.

[6] Buddle, C. M., Spence, J. R., Langor, D. W. (2000): Succession of boreal forest spider assemblages following wildfire and harvesting. - Ecography 23:424-436.

[7] Budja, U.(2008): Primerjava ocen vrstne pestrosti pajkov (Arachnida: Araneae) v treh gozdovih v Sloveniji (Diploma). - University of Ljubljana, Ljubljana.

[8] Buffington, M. L., Redak, R. A. (1998): A comparison of vacuum sampling versus sweepnetting for arthropod biodiversity measurements in California coastal sage scrub. - J. Insect Conserv. 2:99-106.

[9] Cardoso, P. (2009): Standardization and optimization of arthropod inventories-the case of Iberian spiders. - Biodivers. Conserv. 18:3949-3962.

[10] Cardoso, P., Gaspar, C., Pereira, L. C., Silva, I., Henriques, S. S., da Silva, R. R., Sousa, P.(2008): Assessing spider species richness and composition in Mediterranean cork oak forests. - Acta Oecologica-Int. J. Ecol. 33:114-127.

[11] Cardoso, P., Henriques, S. S., Gaspar, C., Crespo, L. C., Carvalho, R., Schmidt, J. B., Sousa, P., Szuts, T. (2009): Species richness and composition assessment of spiders in a Mediterranean scrubland. - J. Insect Conserv. 13:45-55. 
[12] Coddington, J. A., Agnarsson, I., Miller, J. A., Kuntner, M., Hormiga, G. (2009): Undersampling bias: the null hypothesis for singleton species in tropical arthropod surveys. - J. Anim. Ecol. 78:573-584.

[13] Coddington, J. A., Griswold, C. E., Davila, D. S., Penaranda, E., Larcher, S. F. (1991): Designing and testing sampling protocols to estimate biodiversity in tropical ecosystems. Unity Evol. Biol. Proc. Fourth Int. Congr. Syst. Evol. Biol. 1990:44-60.

[14] Coddington, J. A., Levi, H. W.(1991): Systematics and evolution of spiders (Araneae). Annu. Rev. Ecol. Syst. 22:565-592.

[15] Coddington, J. A., Young, L. H., Coyle, F. A., (1996): Estimating spider species richness in a southern Appalachian cove hardwood forest. - J. Arachnol. 24:111-128.

[16] Colwell, R. K.(2013): EstimateS: Statistical estimation of species richness and shared species from samples. Version 9 and earlier. User's Guide and application. Published at: http://purl.oclc.org/estimates.

[17] Colwell, R. K., Coddington, J. A. (1994): Estimating Terrestrial Biodiversity through Extrapolation. Philos. Trans. R. Soc. Lond. Ser. B-Biol. Sci. 345:101-118.

[18] De Souza, A. L. T., Martins, R. P. (2004): Distribution of plant-dwelling spiders: Inflorescences versus vegetative branches. - Austral Ecol. 29:342-349.

[19] De Thoisy, B., Brosse, S., Dubois, M. A. (2008): Assessment of large-vertebrate species richness and relative abundance in Neotropical forest using line-transect censuses: what is the minimal effort required? - Biodivers. Conserv. 17:2627-2644.

[20] Dietrick, E. J.(1961): An Improved Backpack Motor Fan for Suction Sampling of Insect Populations. - J. Econ. Entomol. 54:394-395.

[21] Dinter, A. (1995): Estimation of epigeic spider population densities using an intensive Dvac sampling technique and comparison with pitfall trap catches in winter wheat. - Acta Jutl. 70: 23-32

[22] Dobyns, J. R. (1997): Effects of sampling intensity on the collection of spider (Araneae) species and the estimation of species richness. - Environ. Entomol. 26:150-162.

[23] Favila, M. E., Halffter, G. (1997): The use of indicator groups for measuring biodiversity as related to community structure and function. - Acta Zool Mex 72:1-25.

[24] Gotelli, N. J., Colwell, R. K. (2010): Estimating species richness. Biol. Divers. Front. Meas. Assess. E Magurran B J McGill Eds 39-54.

[25] Green, J. (1999): Sampling method and time determines composition of spider collections. - J. Arachnol. 27:176-182.

[26] Greenstone, M. H. (1984): Determinants of web spider species diversity: vegetation structural diversity vs. prey availability. - Oecologia 62:299-304.

[27] Gregory, R. D., Noble, D., Field, R., Marchant, J., Raven, M., Gibbons, D. W.(2003): Using birds as indicators of biodiversity. - Ornis Hung. 12-13:11-24.

[28] Grootaert, P., Poollet, M., Dekoninck, W., van Achterberg, C. (2010): Sampling insects: general techniques, strategies and remarks. Man. Field Rec. Tech. Protoc. Taxa Biodivers. Invent. Monit. Abc Taxa Belg. Dev. Coop. 1-138.

[29] Groves, C. R., Jensen, D. B., Valutis, L. L., Redford, K. H., Shaffer, M. L., Scott, J. M., Baumgartner, J. V., Higgins, J. V., Beck, M. W., Anderson, M. G. (2002): Planning for biodiversity conservation: Putting conservation science into practice. - Bioscience 52:499-512.

[30] Humphries, C., Parenti, L. (1999): Cladistic biogeography: interpreting patterns of animal and plant distributions. - Oxford University Press, Oxford.

[31] Humphries, C. J., Williams, P. H., Vanewright, R. I. (1995): Measuring biodiversity value for conservation. - Annu. Rev. Ecol. Syst. 26:93-111.

[32] Jimenez-Valverde, A., Lobo, J. M. (2006): Establishing reliable spider (Araneae, Araneidae and Thomisidae) assemblage sampling protocols: estimation of species richness, seasonal coverage and contribution of juvenile data to species richness and composition. - Acta Oecologica-Int. J. Ecol. 30:21-32. 
[33] Kremen, C., Colwell, R. K., Erwin, T. L., Murphy, D. D., Noss, R. F., Sanjayan, M. A. (1993): Terrestrial Arthropod Assemblages: Their Use in Conservation Planning. Conserv. Biol. 7:796-808.

[34] Kuntner, M. (1996): Prispevek k poznavanju favne pajkov Kozjanskega, vzhodna Slovenija (Arachnida: Araneae). - In: Bedjanic, M. (Ed.) Raziskovalni Tabor Studentov Biologije Kozje '95. Zveza organizacij za tehnično kulturo, Gibanje znanost mladini, Ljubljana, pp. 49-60.

[35] Kuntner, M. (1997): Prispevek k poznavanju favne pajkov jugozahodne Slovenije in ugotavljanje vrstnega bogastva pajkov gozda na Brkinih (Arachnida: Araneae). In: Bedjanic, M. (Ed.) Raziskovalni Tabor Studentov Biologije Podgrad '96. Zveza organizacij za tehnično kulturo, Gibanje znanost mladini, Ljubljana, pp. 11-32.

[36] Kuntner, M. (1999): Prispevek k poznavanju favnistike in ekologije pajkov severovzhodne Slovenije (Arachnida: Araneae). - Nat. Slov. 1:29-44.

[37] Kuntner, M., Kostanjšek, R. (2000): Prispevek k poznavanju favne pajkov zahodne Slovenije (Arachnida: Araneae). - Nat. Slov. 2:13-28.

[38] MacLeod, R., Herzog, S. K., Maccormick, A., Ewing, S. R., Bryce, R., Evans, K. L. (2011): Rapid monitoring of species abundance for biodiversity conservation: consistency and reliability of the MacKinnon lists technique. - Biol. Conserv. 144:1374-1381.

[39] Magurran, A. E. (1988): Ecological Diversity and Its Measurement. - Springer Netherlands.

[40] Magurran, A. E. (2004): Measuring Biological Diversity. - Blackwell publishing.

[41] Marc, P., Canard, A., Ysnel, F. (1999): Spiders (Araneae) useful for pest limitation and bioindication. - Agric. Ecosyst. Environ. 74:229-273.

[42] May, R. M. (1988): How many species are there on earth? - Science 247:1441-1449.

[43] Medobčinski Uradni vestnik (1992): Odlok o razglasitvi naravnih znamenitosti na območju občine Maribor. Medobčinski Uradni Vestn.

[44] Merlo, M. J., Parietti, M., Etchegoin, J. A. (2010): Evaluation of species richness estimators in studies of diversity involving two larval digenean communities parasitizing snail hosts. - Parasitol. Res. 107:1093-1102.

[45] Muelelwa, M. I., Foord, S. H., Dippenaar-Schoeman, A. S., Stam, E. M. (2010): Towards a standardized and optimized protocol for rapid biodiversity assessments: spider species richness and assemblage composition in two savanna vegetation types. - Afr. Zool. 45:273-290.

[46] Myers, N., Mittermeier, R. A., Mittermeier, C. G., da Fonseca, G. A. B., Kent, J. (2000): Biodiversity hotspots for conservation priorities. - Nature 403:853-858.

[47] Petillon, J., Garbutt, A. (2008): Success of managed realignment for the restoration of salt-marsh biodiversity: preliminary results on ground-active spiders. - J. Arachnol. 36:388-393.

[48] Pirnat, J. (1991): Nekateri krajinsko ekološki vidiki prosto rastočih dreves v agrarni krajini - nekatere vloge teh dreves v agrarni krajini. Zb. Gozdarstva Lesar. 38:161-184.

[49] Pirnat, J. (2000): Conservation and management of forest patches and corridors in suburban landscapes. - Landsc. Urban Plan. 52:135-143.

[50] Platnick, N. (1999): Dimensions of biodiversity: targeting megadiverse groups. Living Planet Biodivers. Sci. Policy 33-52.

[51] Raven, P. H., Wilson, E. O. (1992): A Fifty-Year Plan for Biodiversity Surveys. - Science 258:1099-1100.

[52] Regan, H. M., Davis, F. W., Andelman, S. J., Widyanata, A., Freese, M. (2007): Comprehensive criteria for biodiversity evaluation in conservation planning. - Biodivers. Conserv. 16:2715-2728.

[53] Ryndock, J. A., Stratton, G. E., Brewer, J. S., Holland, M. M. (2012): Differences in Spider Community Composition among Adjacent Sites during Initial Stages of Oak Woodland Restoration. - Restor. Ecol. 20:24-32. 
[54] Samu, F., Nemeth, J., Kiss, B. (1997): Assessment of the efficiency of a hand-held suction device for sampling spiders: improved density estimation or oversampling? - Ann. Appl. Biol. 130:371-378.

[55] Sanders, D., Entling, M. H. (2011): Large variation of suction sampling efficiency depending on arthropod groups, species traits, and habitat properties. - Entomol. Exp. Appl. 138:234-243.

[56] Scharff, N., Coddington, J. A., Griswold, C. E., Hormiga, G., Bjorn, P. D. (2003): When to quit? Estimating spider species richness in a northern European deciduous forest. $-\mathrm{J}$. Arachnol. 31:246-273.

[57] Schoeman, D. S., Nel, R., Goulart Soares, A. (2008): Measuring species richness on sandy beach transects: extrapolative estimators and their implications for sampling effort. - Mar. Ecol. 29:134-149.

[58] Sergio, F., Newton, I., Marchesi, L., Pedrini, P. (2006): Ecologically justified charisma: preservation of top predators delivers biodiversity conservation. - J. Appl. Ecol. 43:10491055.

[59] Silva, D., Coddington, J., Wilson, D., Sandoval, A. (1996): Spiders of Pakitza (Madre de Dios, Perú): species richness and notes on community structure. Manu Biodivers. Southeast. Perú 253-311.

[60] Sørensen, L. L., Coddington, J. A., Scharff, N. (2002): Inventorying and estimating subcanopy spider diversity using semiquantitative sampling methods in an Afromontane forest. - Environ. Entomol. 31:319-330.

[61] Toti, D. S., Coyle, F. A., Miller, J. A. (2000): A structured inventory of appalachian grass bald and heath bald spider assemblages and a test of species richness estimator performance. - J. Arachnol. 28:329-345.

[62] Tracy, C. R., Brussard, P. F. (1994): Preserving biodiversity: species in landscapes. Ecological Applications 4(2):205-207.

[63] Uetz, G. W. (1991): Habitat structure and spider foraging. In: Habitat Structure. Springer Netherlands, pp. 325-348.

[64] Uradni list RS, št. 49/2004. Uredba o posebnih varstvenih območjih (območjih Natura 2000), 30. 4. 2004

[65] Watts, K., Humphrey, J., Griffiths, M., Quine, C., Ray, D., others, (2005): Evaluating biodiversity in fragmented landscapes: principles. Inf. Note-For. Comm.

[66] Wheater, C. P., Cullen, W. R., Bell, J. R. (2000): Spider communities as tools in monitoring reclaimed limestone quarry landforms. - Landsc. Ecol. 15:401-406.

[67] Wise, D. H. (1993): Spiders in Ecological Webs. - Cambridge University Press.

\section{APPENDIX}

Appendix 1. List of species and thier abundance according to sampling methods for Rače (R) and Marjeta (M) plot. SIF, SW, GRO, AER, BLO and TRAP stand for sifting, sweep net, ground, aerial, blower and pitfall traps, respectively. $D$ - day, $N$ - night. Morphospecies indicated by "sp." are followed by consecutive numbers.

\begin{tabular}{|c|c|c|c|c|c|c|c|c|c|c|c|c|c|c|c|c|c|c|c|c|c|}
\hline & & \multicolumn{2}{|c|}{ SIF D } & \multicolumn{2}{|c|}{ SIF N } & \multicolumn{2}{|c|}{ SW D } & \multicolumn{2}{|c|}{ SW N } & \multicolumn{2}{|c|}{ GRO D } & \multicolumn{2}{|c|}{ GRO N } & \multicolumn{2}{|c|}{ AER D } & \multicolumn{2}{|c|}{ AER N } & \multicolumn{2}{|c|}{ BLO } & \multicolumn{2}{|c|}{ TRAP } \\
\hline & & & M & $\mathrm{R}$ & M & $\mathrm{R}$ & M & $\mathrm{R}$ & M & $\mathrm{R}$ & M & $\mathrm{R}$ & M & $\mathrm{R}$ & M & $\mathrm{R}$ & M & $\mathrm{R}$ & M & $\mathrm{R}$ & M \\
\hline Abacoproeces & saltuum & 1 & & & & & & & & & & & & & & & & & & & \\
\hline Agelena & labyrinthica & & & & 1 & & 2 & & 3 & 1 & 6 & 1 & 3 & & & 1 & & & & & \\
\hline Araneus & angulatus & & & & & & & & 1 & & & & & & & 1 & & & & & \\
\hline Araneus & diadematus & & 1 & & & & 4 & 1 & 2 & & & & 2 & & 7 & & 4 & & & & \\
\hline
\end{tabular}




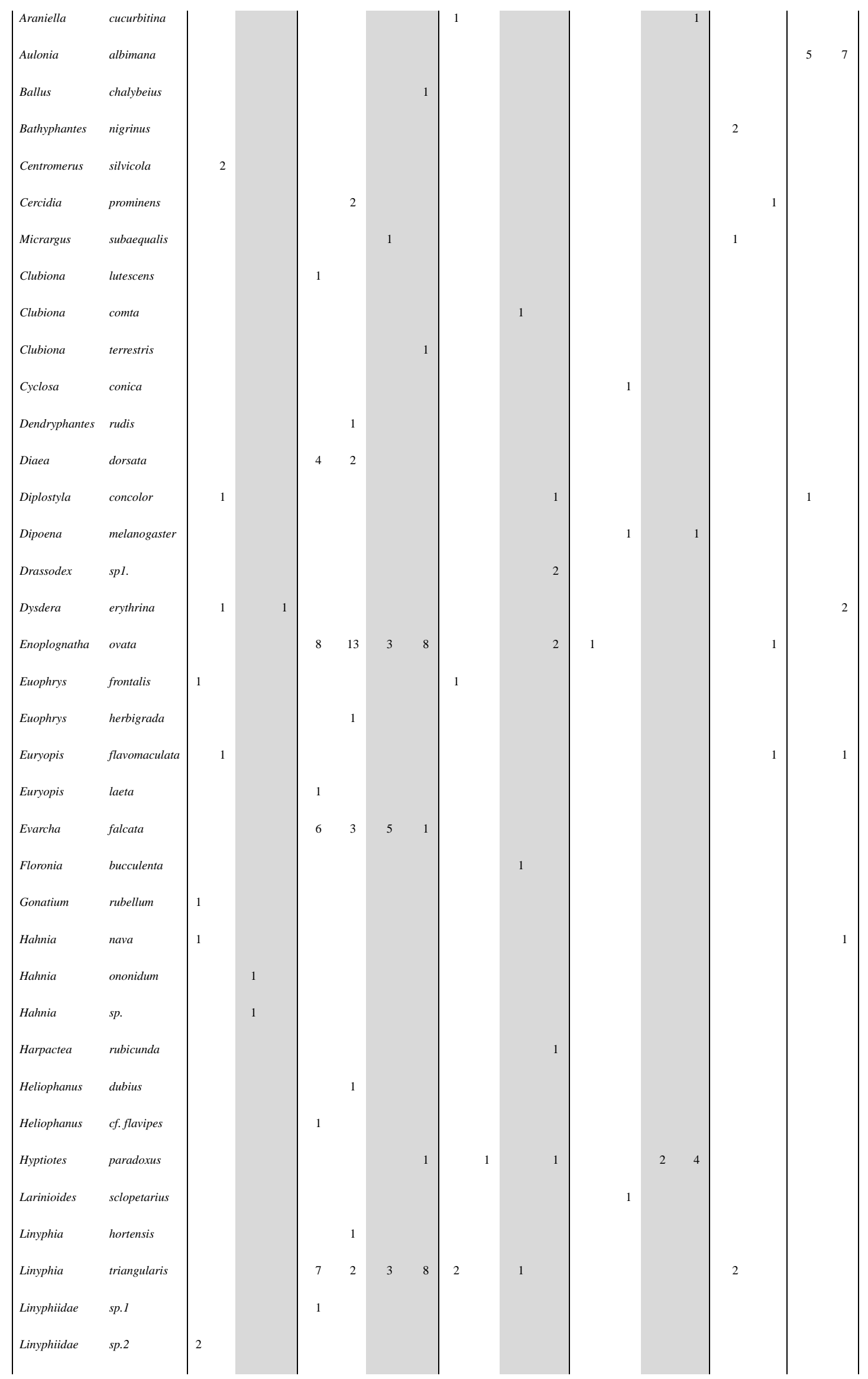




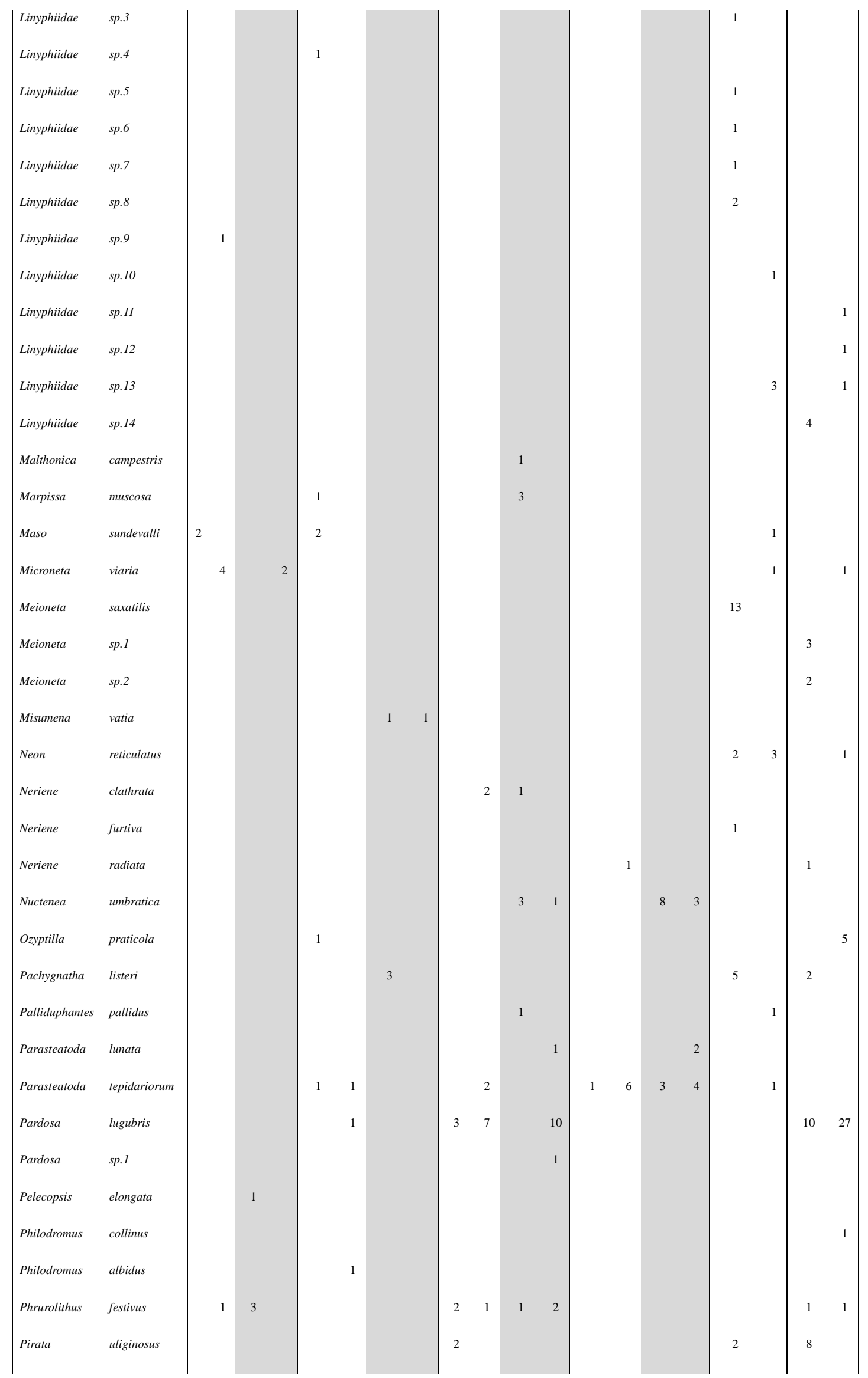




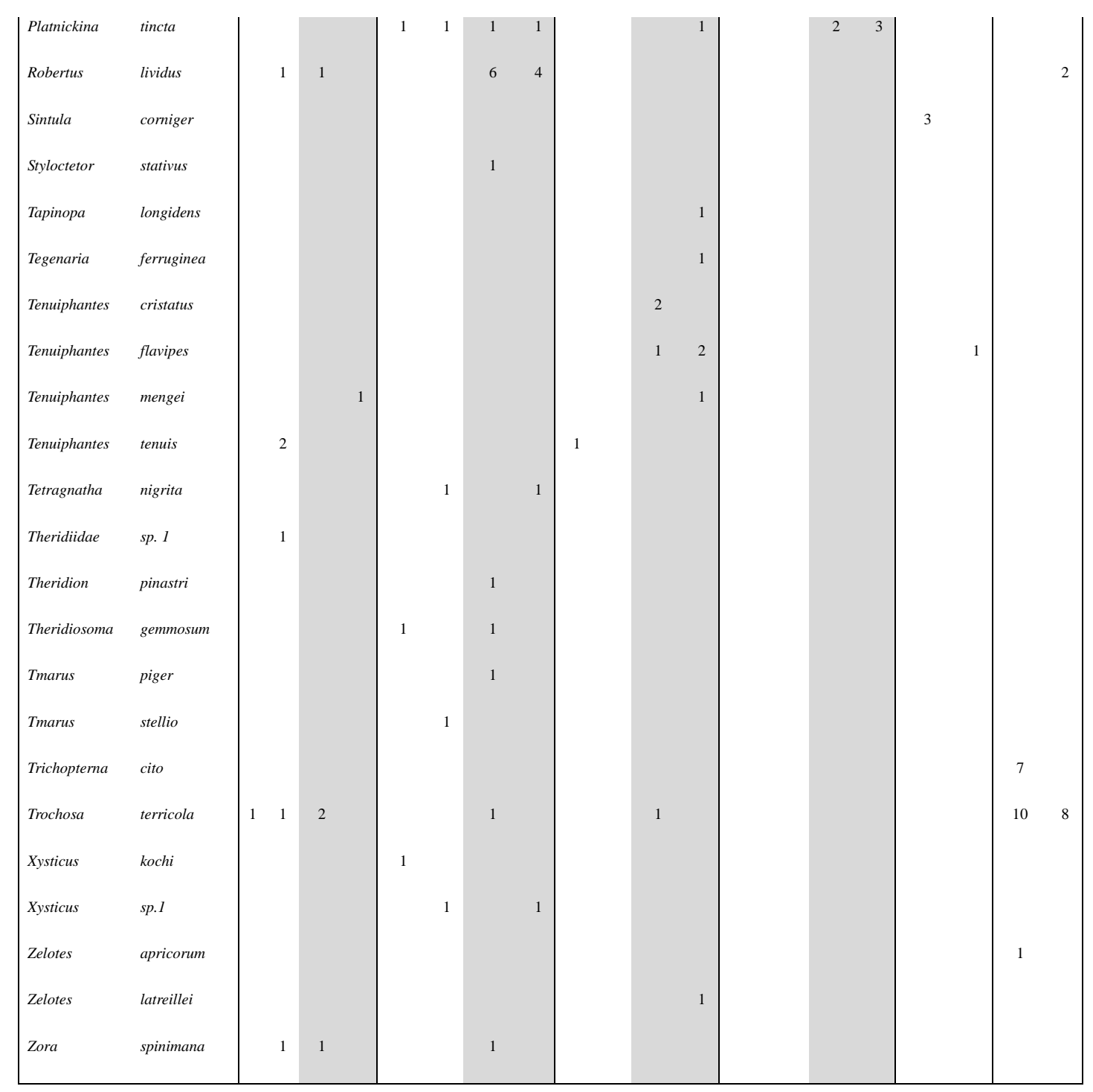

